\title{
Host age effect and expression of cytoplasmic incompatibility in field populations of Wolbachia- superinfected Aedes albopictus
}

\author{
P Kittayapong ${ }^{1}$, P Mongkalangoon ${ }^{1}$, V Baimai ${ }^{1}$ and SL O'Neill ${ }^{2}$ \\ ${ }^{1}$ Department of Biology, Faculty of Science, Mahidol University, Rama 6 Road, Bangkok 10400, Thailand; ${ }^{2}$ Section of Vector \\ Biology, Department of Epidemiology and Public Health, Yale University School of Medicine, 60 College Street, New Haven, CT \\ 06520, USA
}

\begin{abstract}
The Asian tiger mosquito, Aedes albopictus (Skuse), is a known vector of dengue in South America and Southeast Asia. It is naturally superinfected with two strains of Wolbachia endosymbiont that are able to induce cytoplasmic incompatibility $(\mathrm{Cl})$. In this paper, we report the strength of $\mathrm{Cl}$ expression in crosses involving field-caught males. $\mathrm{Cl}$ expression was found to be very strong in all crosses between field males and laboratory-reared uninfected or wAlbA infected young females. In addition, crossing experi-
\end{abstract}

ments with laboratory colonies showed that aged superinfected males could express strong $\mathrm{Cl}$ when mated with young uninfected or wAlbA infected females. These results provide additional evidence that the $\mathrm{Cl}$ properties of Wolbachia infecting Aedes albopictus are well suited for applied strategies that seek to utilise Wolbachia for host population modification.

Heredity (2002) 88, 270-274. DOI: 10.1038/sj/hdy/6800039

Keywords: Aedes albopictus; cytoplasmic incompatibility; host age; Wolbachia

\section{Introduction}

The Asian tiger mosquito, Aedes albopictus (Skuse), is native to Asia and the South Pacific and has been recently introduced into the continental United States and South America (Kambhampati and Rai, 1991; Kambhampati et al, 1991). Ae. albopictus is known to be an important vector of dengue in Southeast Asia (Gould et al, 1968; Chan et al, 1971) and has been implicated in a recent dengue outbreak in Mexico (Ibanez-Bernal et al, 1997). Maternally inherited Wolbachia infections were first found in the ovaries of this mosquito by Wright and Barr (1980). It is now known that nearly all populations of Ae. albopictus are superinfected with two different Wolbachia strains designated wAlbA (A group) and wAlbB (B group) (Sinkins et al, 1995b; Zhou et al, 1998; Kittayapong et al, 2002).

Cytoplasmic incompatibility (CI) is a common phenomenon in insects, caused by Wolbachia (Yen and Barr, 1971) and is known to occur in Ae. albopictus (Kambhampati et al, 1993). When a Wolbachia-infected male mates with an uninfected female, the eggs or embryos die. The net effect is a decrease in the fitness of uninfected females, which over time results in the spread of the infection through the host population (Turelli and Hoffmann, 1991). Individuals may be infected with more than one strain of Wolbachia. Among such superinfected

Correspondence: Dr P Kittayapong, Department of Biology, Faculty of Science, Mahidol University, Rama 6 Road, Bangkok 10400, Thailand. E-mail:grpkt@mahidol.ac.th

Received 13 August 2001; accepted 25 November 2001 individuals, CI occurs if the female is uninfected with respect to the strain that the male carries. The net effect is a decrease in the fitness of single-infected females, and thus the superinfection spreads (Sinkins et al, 1995b). Through the action of CI and related phenotypes, Wolbachia is estimated to have successfully invaded approximately 15-20\% of all insect species (Werren et al, 2000).

The development of transgenic mosquitoes that lack the ability to transmit disease has been suggested as a possible future method for the control of insect-transmitted diseases. This requires a method to introduce and spread transmission-blocking genes into natural vector populations. The phenomenon of CI makes Wolbachia a prime candidate in this endeavor (Sinkins et al, 1997; Curtis and Sinkins, 1998). The success of this long-term goal for disease control is critically dependent on the efficiency of CI expression and maternal transmission of Wolbachia under field conditions (Turelli and Hoffmann, 1999). While these factors have been well studied in Drosophila, little attention has been paid to the dynamics of Wolbachia infections in insects of medical importance. While maternal transmission rates have been examined recently in field populations of Ae. albopictus and shown to be very high (Kittayapong et al, 2002), no studies have examined the expression of CI in field-caught Ae. albopictus. Moreover, in published Drosophila studies a clear difference has been reported between laboratory and field-reared individuals, the latter displaying reduced CI expression (Hoffmann et al, 1990, 1998; Turelli and Hoffmann, 1995). Therefore, the main objective of this study was to investigate the strength of CI expression in field populations of the mosquito vector Ae. albopictus. 
We have also determined whether the age of male hosts has any effect on the expression of CI in this species.

\section{Materials and methods}

\section{Field collection of mosquitoes}

Aedes albopictus were collected from their natural habitats in two different localities approximately $300 \mathrm{~km}$ apart between August 1999 and January 2000. The collection sites were located in Plaeng Yao District, Chachoengsao Province, eastern Thailand and Sai Yok District, Kanchanaburi Province, western Thailand. Two different methods were used to collect Ae. albopictus. First, eggs were collected from several ovitraps placed near bamboo stumps. An ovitrap consisted of a black plastic container lined with a paper towel and half-filled with water. The paper towels containing mosquito eggs were collected from both locations and were brought to the laboratory in Bangkok within a 1-week period. Second, swarming male mosquitoes were collected from locations adjacent to bamboo forests in Chachoengsao and Kanchanaburi Provinces using a simple mosquito net. Live males were put in screen-top containers and were fed with a $10 \%$ sugar solution before being transported to the laboratory in Bangkok on the same day.

\section{Laboratory-reared mosquito strains}

There were three colonies of Ae. albopictus mosquitoes used in the crossing experiments. The superinfected colony (KLPP) was generated in 1997 from crosses between males and females collected from Kanchanaburi Province, western Thailand and the Phi Phi Islands off the west coast of Thailand. The superinfected status of this colony for wAlbA and wAlbB Wolbachia was confirmed by both RFLP analysis of ftsZ PCR products and groupspecific wsp primers as described in Kittayapong et al (2002). The single-infected wAlbA colony (KOH) was established before 1970 from mosquitoes collected at Samui Island (Koh Samui), off the east coast of Thailand and provided by Dr KS Rai, University of Notre Dame, USA. The uninfected colony (UJU) was artificially generated by tetracycline treatment and was provided by Dr Yasushi Otsuka, Oita Medical University, Japan. All these colonies were maintained in the insectary at $27 \pm 2{ }^{\circ} \mathrm{C}$ and with $70 \pm 10 \%$ relative humidity.

\section{Crossing experiments}

Eggs collected from individual ovitraps were placed in separate rearing trays filled with 1 litre of distilled water and larvae were fed fish food. To avoid evaluating individuals from the same cohort, only one male per ovitrap was used in this study. Individual adult males were isolated and allowed to mate for 3 days in a confined cup with either three, 1 to 3-day-old, uninfected females from the UJU laboratory colony, or three, 1 to 3-day-old, $w \mathrm{AlbA}$ infected females from the $\mathrm{KOH}$ colony. After mating, each female was blood-fed with a hamster and allowed to oviposit F1 eggs. The same individual males were then mated again with three, 1 to 3-day-old, superinfected females from the laboratory reared KLPP colony to serve as a control cross. After 3 days, superinfected females were isolated for blood-feeding and egg-laying. Eggs laid by individual females were counted and then allowed to hatch for $24 \mathrm{~h}$ in deoxygenated water. CI expression of the superinfected phenotype was determined by the average number of eggs hatched from each crossing experiment. Single pair crosses between fieldcollected adult males and either UJU or $\mathrm{KOH}$ females were also done as described above.

Several crosses were done between laboratory-reared uninfected, wAlbA infected and $w \mathrm{AlbA}+w \mathrm{AlbB}$ superinfected Ae. albopictus to investigate the effect of host age on CI expression, since it was not possible to determine the exact age of field-collected mosquitoes. In our experiments, the age of males was varied in three different incompatible crosses. These crosses were uninfected females $\times$ superinfected males, wAlbA infected females $\times$ superinfected males, and uninfected females $\times w \mathrm{AlbA}$ infected males. Normal control crosses were performed with 2 to 5-day-old individuals. In these experiments, the age of males was varied from 2-5 days old to $10,20,30$, 40, 50 and 60 days old. Individual males were first aged then mated to young individual females (1-3 days old) using an artificial force-mating technique to ensure that individual pairs were successfully mated. After mating, each female was allowed to oviposit in a confined cup. Eggs laid on each paper towel were left in the wet container to mature, then dried and hatched in distilled water. Spermatheca of individual females were dissected and the presence of sperm was identified by microscopy to confirm insemination. Eggs obtained from mating pairs with no sperm insemination were discarded. CI expression was determined as the average egg hatch rate of each cross. Statistical comparisons of egg hatch rate were performed between methods of collection and between locations using the Mann-Whitney U test from SPSS for windows version 7.5. $P$ values at or below alpha 0.05 were considered significant.

\section{PCR detection of Wolbachia}

After crossing experiments, individual field-collected males were checked for their infection status of Wolbachia (Kittayapong et al, 2002). In this study, we used A and B group specific wsp primers, which were designed from the conserved regions of the outer surface protein gene, to determine the type of infection of individual field-collected mosquitoes (Braig et al, 1998; Zhou et al, 1998). The universal eukaryotic $12 \mathrm{~S}$ rDNA primers (12 SAI and 12 SBI) were also used for checking the quality of DNA extraction (O'Neill et al, 1992). DNA extraction of individual gonad tissues from a colony of laboratory-reared superinfected Ae. albopictus was used as a positive control in the PCR reaction.

Reproductive tissues from individual mosquitoes were used for DNA extraction. The extraction procedure followed the crude boiling method of O'Neill et al (1992). Gonad tissues from individual mosquitoes were dissected under distilled water on a sterile microscope slide and were then homogenised in $100 \mu \mathrm{l}$ of STE buffer. Homogenates were heated at $95^{\circ} \mathrm{C}$ for $10 \mathrm{~min}$ and were centrifuged at $14000 \mathrm{rpm}$ for $1 \mathrm{~min}$. Supernatant of $1 \mu \mathrm{l}$ from individual mosquitoes was used in each $20-\mu l$ reaction volume. Each PCR reaction mixture contained $2 \mu \mathrm{l}$ $10 \times$ buffer (Promega), $2 \mu l 25 \mathrm{mM} \mathrm{MgCl}, 0.5 \mu \mathrm{l}$ dNTPs (10 mM each), $0.5 \mu l$ of each primer and 1 unit of Taq DNA polymerase (Promega). The temperature profile for PCR was as follows: $95^{\circ} \mathrm{C}$ for $3 \mathrm{~min}$, followed by 30 cycles of $95^{\circ} \mathrm{C}$ for $1 \mathrm{~min}, 50^{\circ} \mathrm{C}$ for $1 \mathrm{~min}$ and $72^{\circ} \mathrm{C}$ for $1 \mathrm{~min}$ per cycle. Ten $\mu$ l of each PCR product was electrophoresed 
Table 1 Results of crossing experiments between field-collected adult males and 1-3 days old, uninfected (UJU), single wAlbA infected $(\mathrm{KOH})$ or superinfected (KLPP) laboratory-reared females

\begin{tabular}{|c|c|c|c|c|c|}
\hline \multirow[t]{2}{*}{ Cross } & \multirow[t]{2}{*}{ No. } & \multicolumn{2}{|c|}{ Treatment crosses } & \multicolumn{2}{|c|}{ Control crosses (with KLPP \%) } \\
\hline & & $\begin{array}{l}\text { No. eggs laid } \\
\text { (Mean } \pm \text { S.E.) }\end{array}$ & $\begin{array}{c}\% \text { egg hatch } \\
\text { (Mean } \pm \text { S.E.) }\end{array}$ & $\begin{array}{l}\text { No. eggs laid } \\
\text { (Mean } \pm \text { S.E.) }\end{array}$ & $\begin{array}{c}\% \text { egg hatch } \\
\text { (Mean } \pm \text { S.E.) }\end{array}$ \\
\hline 1. UJU $q \times \mathrm{CH} \sigma^{\circ}$ & 40 & $40.69 \pm 3.11$ & $0.30 \pm 0.19$ & $42.70 \pm 2.87$ & $88.90 \pm 0.82$ \\
\hline 2. $\mathrm{KOH}+\times \mathrm{CH} \mathrm{O}^{0}$ & 40 & $39.03 \pm 2.64$ & $0.19 \pm 0.09$ & $43.02 \pm 2.92$ & $88.40 \pm 0.86$ \\
\hline 3. UJU $+\times$ KL o & 40 & $45.92 \pm 3.92$ & $0.40 \pm 0.19$ & $46.05 \pm 3.12$ & $89.38 \pm 0.70$ \\
\hline 4. $\mathrm{KOH}+\times \mathrm{KL} \mathrm{O}^{\circ}$ & 40 & $43.55 \pm 3.21$ & $0.38 \pm 0.17$ & $51.48 \pm 3.70$ & $90.48 \pm 0.56$ \\
\hline
\end{tabular}

$\mathrm{CH}=$ Chachoengsao; $\mathrm{KL}=$ Kanchanaburi.

on a $1 \%$ agarose gel and was visualised by ethidium bromide staining. The size of the PCR product was determined using a $1 \mathrm{~Kb}$ DNA ladder (Gibco). Expected sizes of the PCR products with A and B group-specific wsp primers were $397 \mathrm{bp}$ and 501 bp respectively.

\section{Results}

\section{Expression of $\mathrm{Cl}$ in field-collected males}

For each cross, a total of 35-40 field-collected adult males from each location were sequentially crossed with either 1 to 3-day-old, laboratory-reared uninfected (UJU) or wAlbA infected $(\mathrm{KOH})$ females and then superinfected (KLPP) females. The cross to UJU females was able to measure the combined CI effect of the superinfection. The cross to $\mathrm{KOH}$ enabled $\mathrm{CI}$ due to the presence of the $w \mathrm{AlbB}$ infection in field males to be evaluated independently of the wAlbA infection. The final cross was a control to verify that the males were fertile, only data from fertile males was subsequently used. Table 1 shows the number of eggs laid by individual females and the percentage of egg hatch from all crosses. CI expression, as determined by egg hatch rate, was very strong (0.19$0.40 \%$ hatching) in all of the crosses between fieldcollected males and young UJU or $\mathrm{KOH}$ females.

In addition to field-caught adults, eggs were collected from field ovitraps and reared in the insectary. The resulting adult males were crossed as above to either UJU or $\mathrm{KOH}$ females, which in all cases resulted in low egg hatch rates $(0.02-0.74 \%$ hatching) as shown in Table 2 . Males derived from ovitraps or caught as adults from swarms show no significant differences in the rate of egg hatch when crossed with either UJU $(P>0.05)$ or $\mathrm{KOH}$ $(P>0.05)$ females. In addition, males collected from dif- ferent locations, eastern or western Thailand, did not show significant differences in the strength of CI expression when crossed with either UJU $(P>0.05)$ or $\mathrm{KOH}(P>0.05)$ females. In control crosses between field males and superinfected females, the mean percent egg hatch ranged between $87.91 \%$ to $91.01 \%$.

\section{Host age effect on $\mathrm{Cl}$ expression}

Results of egg hatch rates from the crosses that varied male age are shown in Table 3. In these crosses, strong CI was expressed at all ages for superinfected KLPP males regardless of whether their young female partners were uninfected or wAlbA infected. There were no viable eggs produced at all male age classes. In the crosses between single infected $\mathrm{KOH}$ males and uninfected females, strong CI expression was observed until the males were 10 days old. The $w$ AlbA infected males that were 20 to 60 days old produced some viable offspring ranging from $18.27 \%$ to $54.44 \%$ egg hatch.

\section{Discussion}

A number of studies have documented a reduction in the strength of Wolbachia-mediated CI expression when old males are used in crosses. This was first characterised for Culex (= fatigans) quinquefasciatus (Singh et al, 1976) and has since been reported for Drosophila simulans (Hoffmann et al, 1986) and Armigeres subalbatus (Jamnongluk et al, 1999). The underlying mechanistic hypothesis is that Wolbachia densities decrease with age of males (Binnington and Hoffmann, 1989; Bressac and Rousset, 1993). However, in the studies reported here, no evidence could be found for this effect in aged superinfected males. When $\mathrm{KOH}$ wAlbA males were aged and

Table 2 Results of crossing experiments between laboratory-raised adult males derived from field ovitrap eggs and 1-3 days old, uninfected (UJU), single wAlbA infected (KOH) or superinfected (KLPP) laboratory-reared females

\begin{tabular}{|c|c|c|c|c|c|}
\hline \multirow[t]{2}{*}{ Cross } & \multirow[t]{2}{*}{ No. } & \multicolumn{2}{|c|}{ Treatment crosses } & \multicolumn{2}{|c|}{ Control crosses (with KLPP ) } \\
\hline & & $\begin{array}{l}\text { No. eggs laid } \\
\text { (Mean } \pm \text { S.E.) }\end{array}$ & $\begin{array}{c}\% \text { egg hatch } \\
(\text { Mean } \pm \text { S.E. })\end{array}$ & $\begin{array}{l}\text { No. eggs laid } \\
\text { (Mean } \pm \text { S.E.) }\end{array}$ & $\begin{array}{c}\% \text { egg hatch } \\
\text { (Mean } \pm \text { S.E.) }\end{array}$ \\
\hline 1. $\mathrm{UJU}+9 \times \mathrm{CH}$ & 40 & $43.99 \pm 3.55$ & $0.02 \pm 0.02$ & $48.48 \pm 3.40$ & $88.94 \pm 0.89$ \\
\hline 2. $\mathrm{KOH}+9 \mathrm{CHO}$ & 38 & $56.08 \pm 4.01$ & $0.74 \pm 0.46$ & $49.00 \pm 3.15$ & $87.91 \pm 0.91$ \\
\hline 3. UJU $9 \times \mathrm{KL} 0^{0}$ & 40 & $41.15 \pm 3.27$ & $0.05 \pm 0.06$ & $48.07 \pm 2.97$ & $91.01 \pm 0.78$ \\
\hline 4. $\mathrm{KOH}+9 \times \mathrm{KL}$ & 40 & $60.60 \pm 4.88$ & $0.49 \pm 0.25$ & $54.55 \pm 4.09$ & $88.78 \pm 0.82$ \\
\hline
\end{tabular}

$\mathrm{CH}=$ Chachoengsao; $\mathrm{KL}=$ Kanchanaburi. 
Table 3 Results of egg hatch between incompatible crossing types that should show strong CI expression only if males were young. In this experiment, the age of individual males was varied from 2-5 days old to $10,20,30,40,50$, and 60 days old

\begin{tabular}{|c|c|c|c|c|c|c|c|}
\hline \multirow[t]{2}{*}{ Cross } & \multicolumn{7}{|c|}{ Percent egg hatch when male age varied ${ }^{a}$} \\
\hline & $2-5 d$ & $10 d$ & $20 d$ & $30 d$ & $40 d$ & $50 d$ & $60 d$ \\
\hline $\begin{array}{l}\text { UJU } q \times \text { KLPP on } \\
\text { No. of pair }(n)\end{array}$ & $\begin{array}{l}0.00[0.30] \\
\quad(10)\end{array}$ & $\begin{array}{l}0.00[0.23] \\
\quad(13)\end{array}$ & $\begin{array}{l}0.00[0.27] \\
\quad(11)\end{array}$ & $\begin{array}{c}0.00[0.27] \\
(11)\end{array}$ & $\begin{array}{l}0.00[0.27] \\
(11)\end{array}$ & $\begin{array}{l}0.00[0.27] \\
\quad(11)\end{array}$ & $\begin{array}{l}0.00[0.27] \\
\quad(11)\end{array}$ \\
\hline $\begin{array}{l}\mathrm{KOH}+\times \text { KLPP on } \\
\text { No. of pair }(n)\end{array}$ & $\begin{array}{l}0.00[0.30] \\
\quad(10)\end{array}$ & $\begin{array}{l}0.00[0.27] \\
\quad(11)\end{array}$ & $\begin{array}{l}0.00[0.27] \\
\quad(11)\end{array}$ & $\begin{array}{l}0.00[0.30] \\
\quad(10)\end{array}$ & $\begin{array}{l}0.00[0.30] \\
\quad(10)\end{array}$ & $\begin{array}{l}0.00[0.30] \\
\quad(10)\end{array}$ & $\begin{array}{l}0.00[0.23] \\
\quad(13)\end{array}$ \\
\hline $\begin{array}{l}\text { UJU } q \times \mathrm{KOH} \sigma^{\prime} \\
\text { No. of pair }(n)\end{array}$ & $\begin{array}{l}0.00[0.30] \\
\quad(10)\end{array}$ & $\begin{array}{l}18.27 \pm 9.72 \\
\quad(11)\end{array}$ & $\begin{array}{c}30.60 \pm 10.28 \\
(12)\end{array}$ & $\begin{array}{l}23.74 \pm 4.13 \\
(10)\end{array}$ & $\begin{array}{c}54.44 \pm 9.07 \\
(10)\end{array}$ & $\begin{array}{c}33.47 \pm 10.44 \\
(10)\end{array}$ & $\begin{array}{c}43.58 \pm 11.02 \\
(10)\end{array}$ \\
\hline
\end{tabular}

${ }^{\mathrm{a}}$ Mean \pm S.E. or mean (95\% upper confident limit). $\mathrm{KOH}=$ single $w \mathrm{AlbA}$ infected; $\mathrm{KLPP}=w \mathrm{AlbA}+w \mathrm{AlbB}$ superinfected; UJU $=$ uninfected

then mated, a pronounced weakening of CI was detected which mirrored studies in other species. The $\mathrm{KOH}$ strain has been shown to be infected at much lower densities than superinfected strains (Sinkins et al, 1995a) and as such might be more susceptible to density related aging effects. Considering that nearly all individuals sampled from field populations to date have been shown to be superinfected (Kittayapong et al, 2002), it would indicate that male age effects should not be influencing CI dynamics in the field.

Adult males caught from the field, transported back to the lab and mated to colony females all produced strong $\mathrm{CI}$, indicating that field rearing does not appear to influence the strength of CI expression in this mosquito species. This is in contrast to studies with Drosophila that have indicated that CI expression can be much stronger in the laboratory than the field (Hoffmann et al, 1998). In our study, no difference was seen between laboratory or field-reared individuals. Turelli and Hoffmann (1999) have suggested that in order for Wolbachia to be used effectively in an applied setting to invade target insect populations, maternal transmission rates and $\mathrm{CI}$ expression should both be high. The results presented in this and previous studies (Kittayapong et al, 2002) indicate that Wolbachia infections of Ae. albopictus, a known dengue vector, have CI properties in the field that suggest Wolbachia may be a better candidate for applied strategies to modify insect vector competence than parameter estimates from Drosophila would initially indicate.

\section{Acknowledgements}

We would like to thank Dr John FY Brookfield for his statistical advice; Rosie G Sharpe and Kathy J Baisley for their suggestions on the CI study using ovitrap mosquitoes; Thanong Aimmak and Somboon Srimarat for their help to collect field mosquitoes and to monitor field ovitraps throughout this study; Kitti Theinthong for his insectary work; and Samnieng Theinthong and Natchaya Klinpikul for their laboratory assistance. This work was supported by the TRF/BIOTEC Special Program for Biodiversity Research and Training (BRT 139026) and the Thailand Research Fund (RTA/01/2541).

\section{References}

Binnington KC, Hoffmann AA (1989). Wolbachia-like organisms and cytoplasmic incompatibility in Drosophila simulans. J Invert Pathol 54: 344-352.
Braig HR, Zhou W, Dobson S, O’Neill SL (1998). Cloning and characterization of a gene encoding the major surface protein of the bacterial endosymbiont Wolbachia. J Bacteriol 180: 2373-2378.

Bressac C, Rousset F (1993). The reproductive incompatibility system in Drosophila simulans: DAPI-staining analysis of the Wolbachia symbionts in sperm cysts. J Invert Pathol 61: 226-230.

Chan YC, Ho BC, Chan KL (1971). Aedes aegypti (L.) and Aedes albopictus (Skuse) in Singapore City: V. Observations in relation to dengue haemorrhagic fever. Bull Wld Hlth Org 44: 651-658.

Curtis CF, Sinkins SP (1998). Wolbachia as a possible means of driving genes into populations. Parasitology 116: 111-115.

Gould DJ, Yuill TM, Moussa MA, Simasathien P, Rutledge LC (1968). An insular outbreak of dengue haemorrhagic fever. III. Identification of vectors and observations on vector ecology. Am J Trop Med Hyg 17: 609-618.

Hoffmann AA, Hercus M, Dagher H (1998). Population dynamics of the Wolbachia infection causing cytoplasmic incompatibility in Drosophila melanogaster. Genetics 148: 221-231.

Hoffmann AA, Turelli M, Harshman LG (1990). Factors affecting the distribution of cytoplasmic incompatibility in Drosophila simulans. Genetics 126: 933-948.

Hoffmann AA, Turelli M, Simmons GM (1986). Unidirectional incompatibility between populations of Drosophila simulans. Evolution 40: 692-701.

Ibanez-Bernal S, Briseno B, Mutebi JP, Argot E, Rodriguez G, Martinez-Campos C et al (1997). First record in America of Aedes albopictus naturally infected with dengue virus during the 1995 outbreak at Reynosa, Mexico. Med Vet Entomol 11: 305-309.

Jamnongluk W, Kittayapong P, O'Neill SL (2000). Wolbachia infection and expression of cytoplasmic incompatibility in Armigeres subalbatus (Diptera: Culicidae). J Med Entomol 37: 53-57.

Kambhampati S, Black WC, Rai KS (1991). Geographical origin of the U.S. and Brazilian Aedes albopictus inferred from allozyme analysis. Heredity 67: 85-94.

Kambhampati S, Rai KS (1991). Mitrochondrial DNA variation within and among populations of the mosquito Aedes albopictus. Genome 34: 288-292.

Kambhampati S, Rai KS, Burgun SJ (1993). Unidirectional cytoplasmic incompatibility in the mosquito, Aedes albopictus. Evolution 47: 673-677.

Kittayapong P, Baisley KJ, Sharpe RG, Baimai V, O'Neill SL (2002). Maternal transmission efficiency of Wolbachia superinfections in Aedes albopictus populations in Thailand. Am J Trop Med Hyg 65: (in press).

O'Neill SL, Giordano R, Colbert AME, Karr TL, Robertson HM (1992). 16S rRNA phylogenetic analysis of the bacterial endosymbionts associated with cytoplasmic incompatibility in insects. Proc Natl Acad Sci USA 89: 2699-2702.

Singh KRP, Curtis CF, Krishnamurthy BS (1976). Partial loss of 
cytoplasmic incompatibility with age in males of Culex fatigans Wied Ann Trop Med Parasitol 70: 463-466.

Sinkins SP, Braig HR, O'Neill SL (1995a). Wolbachia pipientis: bacterial density and unidirectional cytoplasmic incompatibility between infected populations of Aedes albopictus. Exp Parasitol 81: 284-291.

Sinkins SP, Braig HR, O'Neill SL (1995b). Wolbachia superinfections and the expression of cytoplasmic incompatibility. Proc $R$ Soc Lond B 261: 325-330.

Sinkins SP, Curtis CF, O'Neill SL (1997). The potential application of inherited symbiont systems to pest control. In: O'Neill SL, Hoffmann AA, Werren JH (eds) Influential Passengers: Inherited Microorganisms and Arthropod Reproduction, Oxford University Press: Oxford. pp 155-157.

Turelli M, Hoffmann AA (1991). Rapid spread of an inherited incompatibility factor in Californian Drosophila. Nature 353: 440-442.
Turelli M, Hoffmann AA (1995). Cytoplasmic incompatibility in Drosophila simulans: dynamics and parameter estimates from natural populations. Genetics 140: 1319-1338.

Turelli M, Hoffmann AA (1999). Microbe-induced cytoplasmic incompatibility as a mechanism for introducing transgenes into arthropod populations. Insect Molec Biol 8: 243-255.

Werren JH, Windsor DM (2000). Wolbachia infection frequency in insects: evidence of a global equilibrium? Proc $R$ Soc Lond B 267: 1277-1285.

Wright JD, Barr AR (1980). The ultrastructure and symbiotic relationships of Wolbachia of mosquitoes of the Aedes scutellaris group. J Ultrastr Res 72: 52-64.

Yen JH, Barr AR (1971). New hypothesis of the cause of cytoplasmic incompatibility in Culex pipiens L. Nature 232: 657-658.

Zhou W, Rousset F, O'Neill SL (1998). Phylogeny and PCRbased classification of Wolbachia strain using wsp gene sequences. Proc R Soc Lond B 265: 509-515. 